\title{
Recurrent Childhood Lymphoblastic Lymphoma
}

National Cancer Institute

\section{Source}

National Cancer Institute. Recurrent Childhood Lymphoblastic Lymphoma. NCI

Thesaurus. Code C9060.

The reemergence of lymphoblastic lymphoma in childhood after a period of remission. 